\title{
DETERMINATION OF GENETIC VARIABILITY BY AFLP AND C-BANDING METHODS IN TETRAPLOID WHEAT (TRITICUM TURGIDUM L.) LANDRACES
}

\author{
Tesfaye Mèssele
}

Department of Biotechnology and Biosafety, Institute of Biodiversity Conservation

PO Box 30726, Addis Ababa, Ethiopia. E-mail: tesfaye2006et@yahoo.co.uk

\begin{abstract}
AFLP provided genetic diversity information for 30 tetraploid wheat (Triticum turgidum L.) representing four sub regions and four altitude classes. For C-banding 14 accessions and one cultivar was studied. Genetic distance values between and within accessions were calculated and grouped by regions and altitude classes. For both AFLP and C-banding similarity and dissimilarity of accessions was analysed by Unweighted 'pair group method with arithmetical average (UPGMA) dendrogram. Geographic classes did not show distinct sub groupings. The presence of unique $\mathrm{C}$ - bands in Ethiopian tetraploid wheat might have resulted from recent translocation events.
\end{abstract}

Key words/phrases: AFLP, C-banding, genetic variability, polymorphism

\section{INTRODUCTION}

Tetraploid wheat (Triticum turgidum L.) landraces are widely cultivated in varied agro-ecological zones of Ethiopia (Tesfaye Tesemma, 1991). In the country, tetraploid wheat is generally chosen for multiple home made food, drinks. It is also valuable source of genetic diversity for crop improvement. Landraces of tetraploid wheat are replaced or on the verge of replacement by improved varieties (Melaku Werede, 1991).

Because of this the Ethiopian genebank has been established to collect and conserve indigenous landraces, including tetraploid wheat. Currently over 12000 tetraploid wheat accessions are collected and maintained in this genebank. Sixty per cent of these collections are characterized using morphological traits, which are based on plant height, flowering and maturity time, ear and seed characters. These traits are controlled by multiple genes; because of this they are prone to environmental conditions (Newbury and Ford, 1993). Phenotypic characterization in general may lead to ineffective characterization and classification (Pfluger et al., 2000). For this reason many of the collections in the genebank remain ineffectively characterized and diversity is not properly measured. Isozyme marker as a tool for wheat characterization and diversity assessment has also been used, however, the number of polymorphism in this marker is limited and their expression has been shown to be affected by environmental condition too (Tsegaye Seifu et al., 1996). Therefore, for efficient characterization and proper maintenance of genebank collections, a technique of higher efficiency, rapidity and reproducibility is required.

Molecular techniques have been successfully used in identifying and reliably assessing genetic diversity in wheat (Paetku and Strobeck, 1994; Barrett and Kidwell, 1998; Karp et al., 1996; Vos et al., 1995; Qi and Lindhout, 1997; Tracy et al., 1996; Plaschke et al., 1995; Edwards et al., 1991). There are many molecular techniques for characterizing genetic resourses. Among them Restriction Fragment Length Polymorphism (RFLP), Random Amplified Polymorphism DNA (RAPD) and AFLP are most used. RFLP, RAPD and AFLP molecular technologies revealed minor differences in DNA sequences, allowing the direct comparison of related genomes and circumventing any environmental effect on gene expression.

However, RFLP technique is a laborious procedure that usually requires radioisotopes and costs of RFLP together with the insufficient reproducibility of the RAPD are major drawbacks and make them less suitable for genetic resources characterization (Vos et al., 1995).

AFLP is more appropriate in characterization of genetic resources than RFLP and RAPD because it is not influenced by environment and most restriction fragments detected correspond to unique position in the genome. The technique can generate fingerprints of any DNA (Vos et al., 1995). AFLP technique enables the analysis of large number of randomly distributed DNA sequences in a single PCR reaction and allows surveying the entire genome more efficiently than RFLP and RAPD. The technique provides in general 30 to 100 genomic bands per lane on high resolution 
polyacrylamid gels (Vos et al., 1995), revealing highest diversity index (Edwards et al., 1992).

Another method that allows effective and reliable identification and diversity analysis of tetraploid wheat is C-banding. This technique is most helpful in the identification of individual chromosome and allows the distinction of chromosome from different genomes (Russel et al., 1997). C-banding has shown to give the highest number of bands in tetraploid wheat species yet known. Based on Russel et al. (1997), A-genome and B-genome chromosomes displayed 150 bands. Chromosomes have constant features that are not altered by environment.

In the present study the AFLP and C-banding techniques were chosen to study the extent of inter and intra genetic diversity in tetraploid wheat accessions.

To properly collect and conserve genetic resources, diversity study of the conserved landraces is a prerequisite. Therefore, the aim of this study was to assess variability and the genetic relationships among 26 IBC accessions of tetraploid wheat landraces and to evaluate the suitability of AFL.P and C-banding markers for genetic diversity study in tetraploid wheat. In this study regional and altitudinal variations were also determined.

\section{MATERIALS AND METHODS}

For this study plant materials of thirty accessions for AFLP study landraces (various bio-types) from the Institute of Biodiversity Conservation (IBC), Addis Ababa, Ethiopia was received. The Ethiopian cultivars 'Boohai (Et1) and Arendato (Et2), from Ethiopian Institute of Agricultural Research and the European cultivars Golden Ball (Er1) and Capeiti. (Er2) obtained from the Centre for Genetic Resources, The Netherlands (CGN) were used as standards for this study. Altitude and regional classes from where these accession were collected are given in Table 1.

Table 1. List of accessions, with their region and altitude of collection.

\begin{tabular}{lccc} 
Altitude & No of accession & Regions & No of accession \\
\hline $1600-2000$ & 7 & North & .7 \\
$2001-2400$ & 7 & East & 7 \\
$2041-2800$ & 7 & West & 7 \\
22800 & 5 & South & 2 \\
\hline
\end{tabular}

Abbreviations used for the regions of collection: Y\&K - Yerer and Kereu (East); G\&M - Gebat and Mecha (West); MNG Mennagesha (West); K\&HH - Kembata and Hadya (South); 'T\&B Tegulet and Bulga (North).

Note: Accession is mixture of biotype. In mixture durum, turgidum and other biotype is available.
The IBC accessions wers collected from the farmers' fields and stores in the region of Shewa. Four sub-regions: East (E), West (W), North (N), South (S) and four classes of altitudes (i.e., 1600$2000 \mathrm{~m}, 2001-2400 \mathrm{~m}, 2401-2800 \mathrm{~m}$ and $2801 \mathrm{~m}$ and higher) were used as classifying variables for the 30 accessions.

All accessions were selfed for two generations. Seeds were randomly selected and planted in the green house in the Department of Genetics, Wagningen, University, The Netherlands. Ten individual plants per accession were used. Each plant was described as an operational taxonomic unit (OTU). From the growing plants ten to eleven days leaves of individual orU was collected and stored in $-80^{\circ} \mathrm{C}$.

\section{DNA extraction and AFLP gel running}

DNA was extracted according to the CTAB protocol published (Gill et al., 1991). Two grams of frozen leaf tissue were homogenised in $3 \mathrm{ml} 2 \%$ CTAB-buffer. The homogenate was incubated at $65^{\circ} \mathrm{C}$ for 90 minutes, while gently mixing at 10 minutes interval. After two chloroform extractions, the DNA was precipitated and dissolved in $0.5 \mathrm{m \ell}$ TE buffer. The total genomic DNA was quantified with a DNA fluorometer, model TKO 100 (San Francisco). DNA partial restriction was avoided using a protocol described in Bio-rad-purification kit.

AFLPS, amplification procedures were followed according to the technique described by Keygene (Vos et al., 1995). The adapter and primer combinations (PCs) used in the experiment are illustrated in Table 2.

Table 2. Primers used for the detection of diversity in tetraploid Ethiopiart wheat landraces and cultivars.

\begin{tabular}{|c|c|c|c|c|}
\hline $\begin{array}{l}\text { Pri- } \\
\text { mers }\end{array}$ & Extension & Sequences & Combined & Primers \\
\hline$\overline{\mathrm{E} 35}$ & $\mathrm{ACA}$ & 5'GACTGCGTACCAATTCACA & $\mathrm{E} 35 \mathrm{M} 37$ & E42M36 \\
\hline E37 & ACG & 5'GACTGCGTACCAATTCACG & E37M36 & E35M36 \\
\hline $\mathrm{E} 42$ & $\mathrm{AGT}$ & 5'GACIGCGTACCAATTCAGT & E37M38 & \\
\hline M36 & $\mathrm{ACC}$ & 5'GATCAGTCCTGAGTAAACC & $\mathrm{E} 37 \mathrm{M} 40$ & \\
\hline M37 & $A C G$ & 5'GATGAGTCCTGAGTAAACG & $\mathrm{E} 35 \mathrm{M} 40$ & \\
\hline M38 & ACT & 5'GATSAGTCCICAGTAAACT & E35M36 & \\
\hline $\mathrm{M} 40$ & $A G C$ & 5'GATGAGTCCTGAGTAAAGC & $\mathrm{E} 42 \mathrm{M} 37$ & \\
\hline
\end{tabular}

Gel running was conducted by mixing the PCR amplification product with $20 \mu \mathrm{L}$ loading buffer. Three microliters of this mixture was applied to $5 \%$ denaturing polyacrylamide gel (39x41 cm in size) and resolved at constant-wattage of $55^{\circ} \mathrm{C}$ (which corresponds with running condition of $2000 \mathrm{~V}$ $90 \mathrm{~mA} .120 \mathrm{~W}$ ) in $1 \times T B E$ running buffer until the first blue dye disappeared. Gel was fixed in $10 \%$ acetic 
acid for $30 \mathrm{mins}$ and dried at $80^{\circ} \mathrm{C}$ for $2 \mathrm{hrs}$. To the dried and cooled gel a film (X-ray film, Konica, $30 \times 40 \mathrm{~cm}$, Japan) was exposed for 3-7 days. This helped to visualize and score AFLP bands.

\section{c-banding}

For 30 accessions, first morphological, AFLP and C-band characterization was conducted. This helped selection of 14 accessions for C-banding study. It was also observed that the accessions were composed of two morph-types: T. turgidum L. cv. group durum and T. turgidum i.e. it was a mixture.

To continue condusting C-banding actively growing root tips were collected in the morning from young plant and pre-treated in ice water for 24 hours. The material was fixed in freshly prepared acetic acid-ethanol (1:3) and stored at $-20^{\circ} \mathrm{C}$ until further use. For preparing chromosome slides root tips were rinsed in distilled water. Mild hydrolysis in 0.2 NHCL for 1 hour at room temperature was done. C-banding technique followed Russel et al. (1997) protocol: Preparations were denatured in saturated barium hydroxide $(6 \%)$ at $37 \mathrm{C}$ for 10 minutes. After a through rinse in running tap water, the material was incubated in $2 \times 5 S C(0.3 \mathrm{~N} \mathrm{NaCl}+.0 .03 \mathrm{~N} \mathrm{Na-citrate,} \mathrm{pH7.0)} \mathrm{at}$ $60^{\circ} \mathrm{C}$ for 1 hour, rinsed in $50 \mathrm{mM}$ phosphate buffer (pH 7.2) and stained in 5\% Giemsa in the same phosphate buffer. The slides were then briefly destained in buffer: and distilled water and air dried. The slides, mounted in Entellan Neu, (Merck), were observed in a bright field microscope.

Chromosome identification was based on the nomenclature for wheat chromosome (Russel $e t$ al., 1997). Chromosomes from at least 5 metaphase plates per accessions were scored for $\mathrm{C}$-banding pattern (Fig. 1). Each pair of A and B chromosomes were distinguished by the presence of diagnostic: C-bands, relative chromosome length, and arm length ratio (Fig. 1 and Table 8).

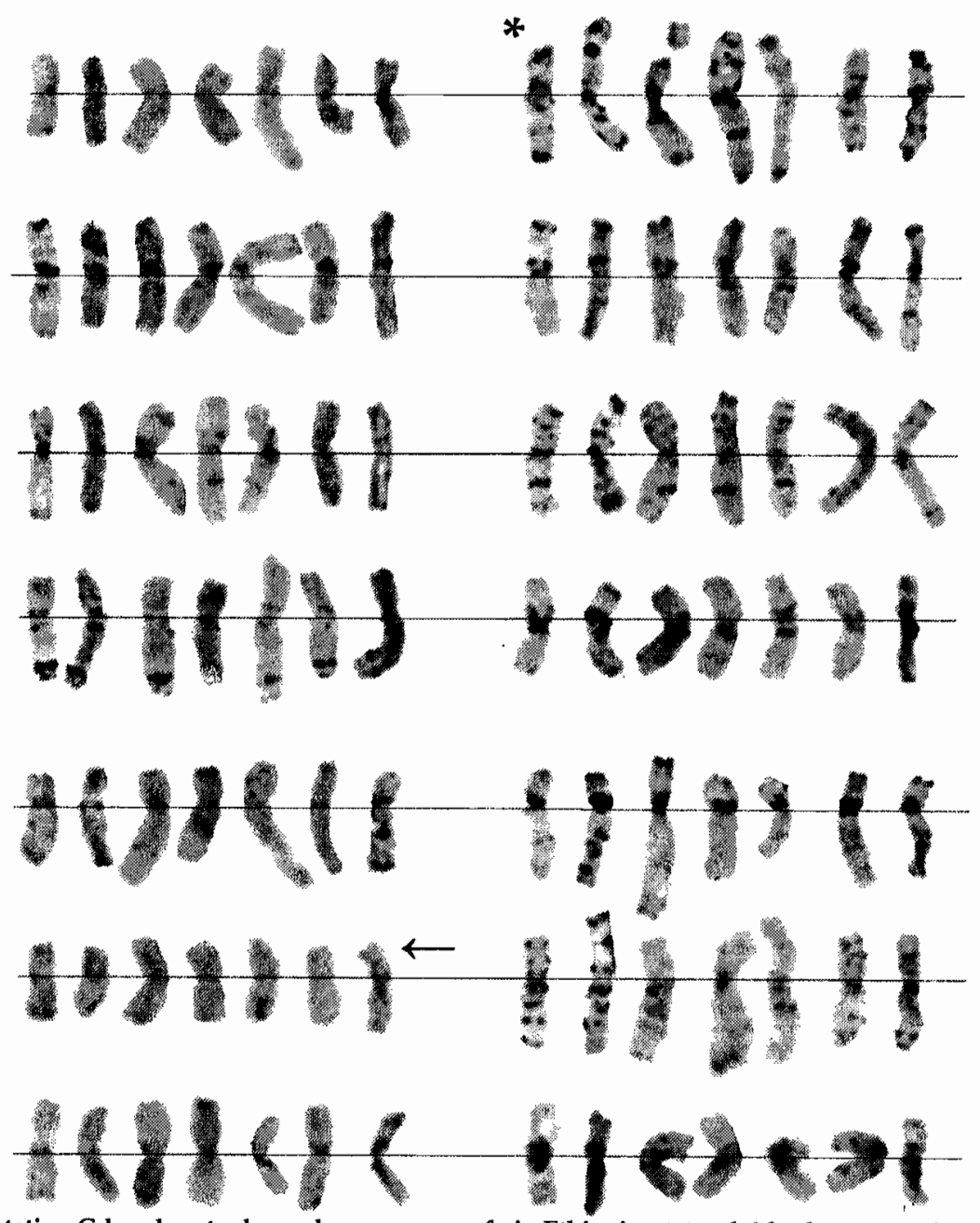

Fig. 1. Representative C-band metaphase chromosomes of six Ethiopian tetraploid wheat accessions and an European durum wheat culivar. [Chromosomes were ordered according to the nomenclature for wheat chromosomes in Gill et al. (1991). Differences in chromosome size are due to contraction variation between metaphase sets. $*$, examples of C-band polymorphisms between the accessions; -typical polymorphisms occurring only in the accessions and not in the cultivar]. 
Where chromosomes were overlapping in a metapahse complement a chromosome from a different complement was used for the karytype. Some variation between cells from the same accession was observed, but these were considered as local differences in Giemsa staining. intensity. Schemes of blocks of C-band chromosomes pattern found in Ethiopian tetraploid wheat are drawn and used for determination of chromosome polymorphism (Fig. 2).

\section{Image capturing and karyotype analysis}

Well spread metaphase plates of C-band preparations were selected and photographed with a Zeiss
Axioskop microscope on 400 iso colour negative film. Images of metaphase: plates and individual chromosomes were further processed with Corel Draw and Adobe phtoshop image processing software programmes. Chromosomal length and arm-ratio measurements were obtained from five complete C-banded cells. Identification of satellited chromosomes was accomplished by comparing captured images of pre-banded phase contrast cells with the same cells following $\mathrm{C}$-banaing.
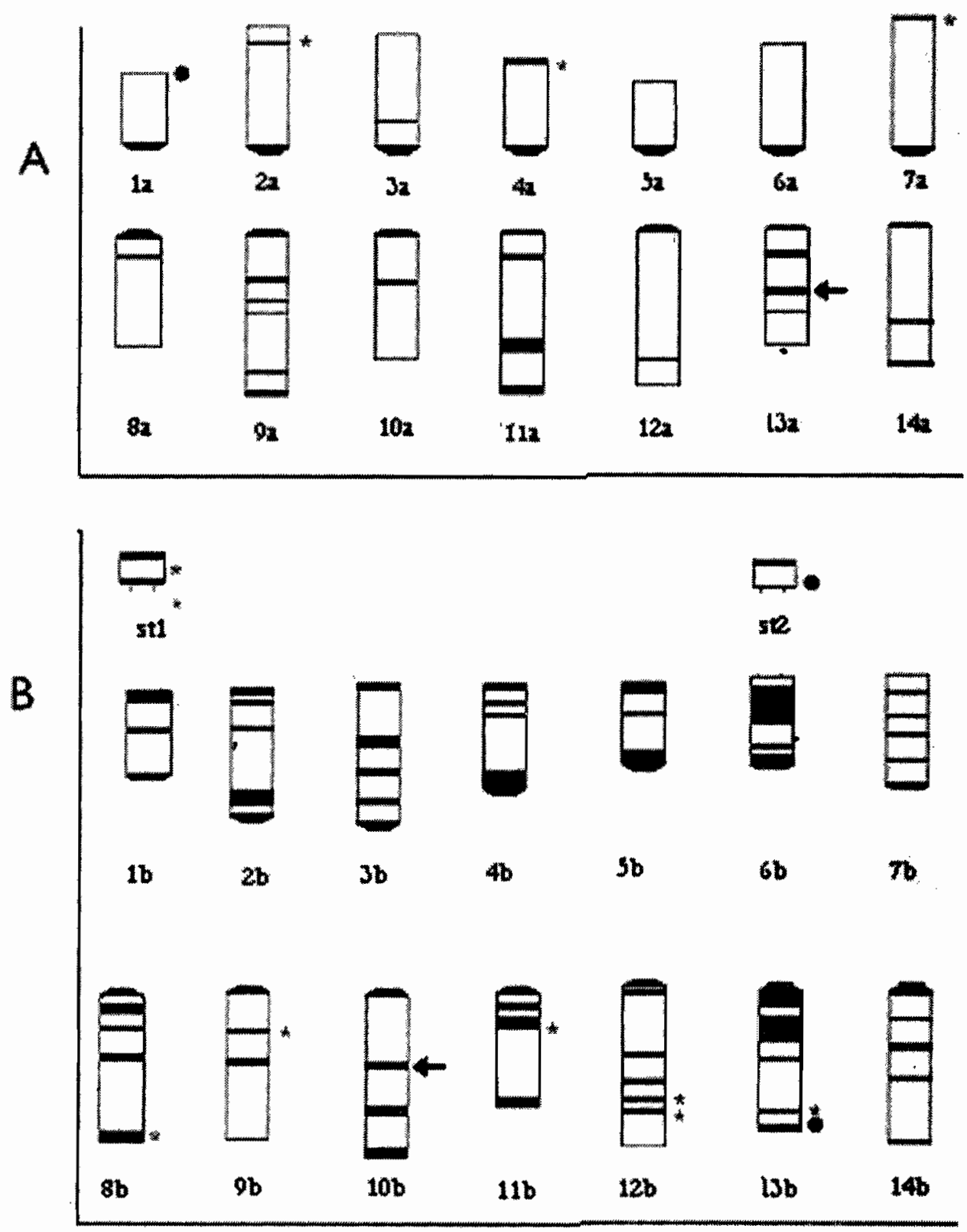

Fig. 2 Catalogue of blocks of C-banding for A and B chromosomes of Ethiopian tetraploid wheat. 


\section{Data analysis}

For AFLP and C-band genetic diversity within accession, geographical regions and altitudes were estimated according to the Shannon Weaver diversity index. The indices were chosen: because AFLP and C-band produce co-dominant data and to see the extent of accession diversity. Shannon Weaver diversity index analysis was calculated on the data obtained from AFLP and C-banding. AFLP and C-banding data were calculated uniformly. The Shannon-Weaver index is given as:

$$
H=n \sum p i \ln P i
$$

$\Sigma$ - used for summation of pi $\ln \mathrm{Pi}, \mathrm{n}$ is the number of phenotypic classes for a band and $p_{i}$ is the proportion of the total number of entries in the $i^{\text {th }}$ class. Pi is the data obtained. $H^{\prime}$ was determined per individual band for a total of 84 polymorphic bands. In order to keep the value of $\mathrm{H}^{\prime}$ in the range. 0 to 1 , each value of $H^{\prime}$ was divided by its maximum value.

AFLP being a dominant marker, band intensity differences were not considered as a polymorphism. Rather the PCR or the gel was re-run when the band is not reproducible.

On eye basis, the presence or absence of AFLP fragments was scored on the autoradiogram (Fig. 3) and transferred into a presence (1) and absence (0) matrix. The phenetic analysis or Jaccards similarity coefficient was performed with the statistical software in NTSYS-pc (Software designed by Robert et al. (1988)). A dendrogram was generated by NTSYS-pc software using the unweighted pair group mathematical analysis (UPGMA).

\section{RESULT}

Using nine AFLP primer combinations (PCs), 300 OTUs representing 30 accessions were analyzed. A total of 540 bands were visualized across all 30 accessions of tetraploid wheat, of which 84 (15.56\%) were different (polymorphic). The frequency of occurrence of band was varied considerably between PCs (Table 3). 'Two to 19 types of banding were registered per PC. Figure 3 shows the typical amplification result using a single PC E37M40 of wheat accessions.

Two bands were not present elsewhere, but only in four accessions: 5946, 6028, 5904, and 7158. Five bands peculiar to two cultivars: Et1 and Er1 were observed. Except few orus a larger group was ob- served producing abundant polymorphism (Table 3). Out of 30, two accessions (5904 and 6028) had relatively high diversity value for all PCs (Table 3 ). The highest differentiation coefficient (Gst) was observed for PCs E37M40 (0.77), E35M40 (0.74) and E42M37 (0.93).

Table 3. Number and per cent polymorphic bands.

\begin{tabular}{ccc}
\hline $\begin{array}{c}\text { Primer } \\
\text { combination }\end{array}$ & Number of bands & \% Polymorphic bands \\
\hline E35M37 & 1379 & 7.2 \\
E37M36 & 982 & 5.2 \\
E37M38 & 743 & 3.7 \\
E37M40 & 625 & 3.2 \\
E35M40 & 144 & 0.8 \\
E35M36 & 198 & 1.3 \\
E42M37 & 331 & 2.31 \\
E42M36 & 127 & 0.8 \\
E35M38 & 355 & 2.4 \\
Mean & 566.12 & 2.99 \\
Total & 4884 & 26.99 \\
\hline
\end{tabular}

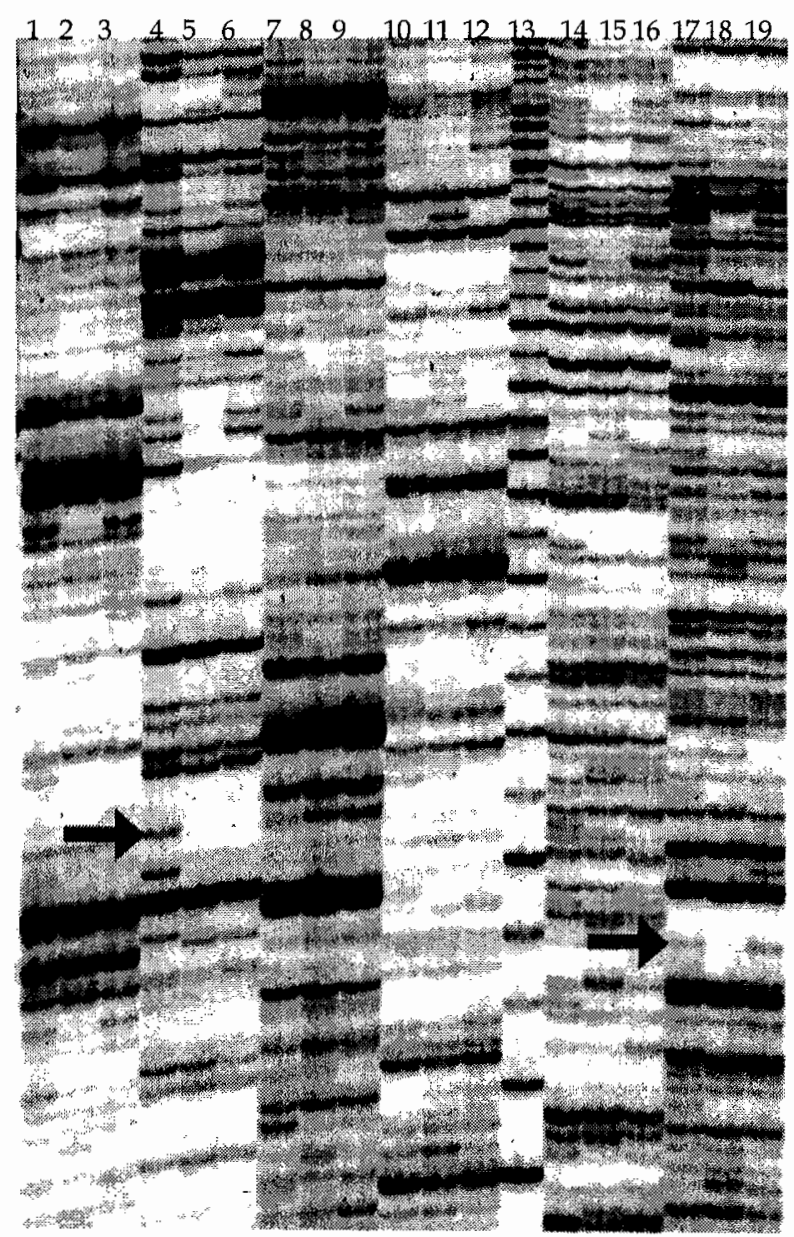

Fig. 3. Representative gel of the AFLP PCR product banding patterns.

(Primers E37M36 was used to amplify tetraploid wheat landraces genomic DNA. (From left to right: Lane 1 and 19 shows control samples Lanes 2 to 18 are tetraploid wheat accessions). 
Total diversity for all accessions ranged from 0.42 to 0.67 . Far higher value for the withinaccession variation $(\mathrm{Hs}=0.33)$ than the among accession (Dst $=0.17$ ) variation was observed. The Gst value for landraces ranged from 0.07 to 0.60 , (Table 4), while for cultivars (standards) is 0.00 to 0.39 (Data not shown). The mean Shannon Weaver genetic diversity value for the turgidum and durum subgroups, and cultivars ranged from 0.1 to 0.5 and 0.1 , respectively (Table 7).

The among mean diversity estimate for altitude
(0.50) and regions (0.44) is higher than the within altitude $(0.04)$ and region $(0.08)$ classes, respectively (Table 5). All, except PC E37M38 exhibited highest diversity value for all altitude and regional classes (Data not shown).

Similarity matrix calculated for possible pair wise comparisons between the 30 accessions showed that the similarity index varied from 0.30 to $0.65 \%$ with an average value of 0.48 and a variation of $60 \%$ (Table 6).

Table 4. Shannon-weaver diversity for within and between accession variations.

\begin{tabular}{lllllllllll}
\hline & \multicolumn{10}{c}{ Primer combinations } \\
\hline Diversity index & E35M37 & E37M36 & E37M38 & E37M40 & E35M40 & E35M36 & E42M37 & E42M36 & E35M38 & Mean \\
\hline Ht & 0.42 & 0.47 & 0.47 & 0.47 & 0.50 & 0.48 & 0.54 & 0.67 & 0.49 & 0.50 \\
Hs & 0.24 & 0.30 & 0.19 & 0.11 & 0.37 & 0.31 & 0.50 & 0.40 & 0.29 & 0.33 \\
Dst & 0.18 & 0.17 & 0.28 & 0.23 & 0.13 & 0.17 & 0.04 & 0.27 & 0.20 & 0.17 \\
Gst & 0.42 & 0.36 & 0.60 & 0.47 & 0.26 & 0.35 & 0.07 & 0.40 & 0.41 & 0.34 \\
\hline
\end{tabular}

Table 5. Shannon-weaver diversity in relation to altitude and sub region.

\begin{tabular}{|c|c|c|c|c|c|c|}
\hline Groups & & & Is & & & Gst \\
\hline Altitude classes I, II, III, IV ' & 0.47 & 0.52 & 0.53 & 0.50 & 0.50 & 0.04 \\
\hline Sub region $E, N, S, W$ & 0.40 & 0.51 & 0.42 & 0.52 & 0.46 & 0.08 \\
\hline
\end{tabular}

Means

Altitudes from I to IV

Regions, $E=$ East, $N=$ North,$S=$ South and $W=$ West.

Table 6. Similarity matrix (Jaccard's similarity index) based on the observed tetraploid wheat C-banding pattern between all possible pairs of 15 accessions. Accessions have been given running numbers as: 1..5909, 2. $6028,3.5946,4.5921,5.5314,6.5375,7.6158,8$. Capati, 9. 6000, 10. 5441, 11. 6038, 12. 7190, 13. 6022, 14. 5904, 15.5588.

\begin{tabular}{|c|c|c|c|c|c|c|c|c|c|c|c|c|c|c|c|}
\hline & 1 & 2 & 3 & 4 & 5 & 6 & 7 & 8 & 9 & 10 & 11 & 12 & 13 & 14 & 15 \\
\hline 1 & 1.0 & & & & & & & & & & & & & & \\
\hline 2 & 0.8 & 1.0 & & & & & & & & & & & & & \\
\hline 3 & 0.8 & 0.9 & 1.0 & & & & & & & & & & & & \\
\hline 4 & 0.6 & 1.0 & 0.4 & 1.0 & & & & & & & & & & & \\
\hline 5 & 0.8 & 0.7 & 0.7 & 0.4 & 1.0 & & & & & & & & & & \\
\hline 6 & 0.8 & 0.8 & 0.7 & 0.3 & 0.6 & 1.0 & & & & & & & & & \\
\hline 7 & 0.7 & 0.8 & 0.6 & 0.4 & 0.5 & 0.7 & 1.0 & & & & & & & & \\
\hline 8 & 0.8 & 0.8 & 0.7 & 0.6 & 0.9 & 0.8 & 0.8 & 1.0 & & & & & & & \\
\hline 9 & 0.8 & 0.8 & 0.4 & 0.5 & 0.5 & 0.4 & 0.4 & 0.5 & 1.0 & & & & & & \\
\hline 10 & 0.6 & 0.8 & 0.4 & 0.8 & 0.6 & 0.5 & 0.4 & 0.7 & 0.6 & 1.0 & & & & & \\
\hline 11 & 0.8 & 0.8 & 0.7 & 0.6 & 0.6 & 0.6 & 0.6 & 0.8 & 0.4 & $\cdot 0.7$ & 1.0 & & & & \\
\hline 12 & 0.7 & 0.8 & 0.4 & 0.5 & 0.5 & 0.3 & 0.5 & 0.6 & 0.4 & 0.8 & 0.5 & 1.0 & & & \\
\hline 13 & 0.8 & 0.9 & 0.6 & 0.9 & 0.5 & 0.5 & 0.6 & 0.6 & 0.5 & 0.6 & 0.7 & 0.7 & 1.0 & & \\
\hline 14 & 0.7 & 0.8 & $0.7^{\circ}$ & 0.4 & 0.7 & 0.6 & 0.6 & 0.6 & 0.7 & 0.7 & 0.7 & 0.7 & 0.5 & 1.0 & \\
\hline 15 & 0.8 & 0.9 & 0.5 & 0.6 & 0.5 & 0.4 & 0.5 & 0.6 & 0.5 & 0.7 & 0.6 & 0.8 & 0.9 & 0.6 & 1.0 \\
\hline
\end{tabular}


In a few cases individual genotypes (durum and turgidum) were uniquely identified by their banding pattern. However, compared to turgidum, durum had abundant polymorphism (Table 7).

The relati nship among individual accessions illustrated by the UPGMA analysis of Jaccards similarity coefficients indicated major divergence between landraces and two cultuvars (controls). The IBC accessions grouped into three stab groups with a similarity level of 0.3 to $0.55 \%$ among the 26 accessions (Fig 4). However, in Migure 4 chs serving by altitude and sub region classes not informative enough for diversity assessment and conservation by and large.

Tabl : 7. Shannon-weaver diversity values for durum and turgidum and numbers of polynorphic bands par primer combination.

\begin{tabular}{lcccccccc}
\hline Primer combination & \multicolumn{4}{c}{ Shannon Weaver diversity } & \multicolumn{3}{c}{ No of polymorphic bands } \\
\cline { 2 - 9 } & Durum & Turgidum & Et1 & En2 & Er1 & Er2 & Durum & Turgidurim \\
\hline E35M37 & 0.4 & 0.2 & 0.1 & 0.3 & 0.3 & 0.3 & 14 & 13 \\
E37M36 & 0.5 & 0.2 & 0.2 & 0.2 & 0.3 & 0.2 & 11 & 10 \\
37M38 & 0.5 & 0.2 & 0.3 & 0.2 & 0.2 & 0.2 & 9 & 8 \\
E37M40 & 0.5 & 0.2 & 0.2 & 0.2 & 0.2 & 0.3 & 7 & 9 \\
E35M40 & 0.5 & 0.1 & 0.3 & 0.2 & 0.2 & 0.3 & 3 & 4 \\
E35M36 & 0.5 & 0.1 & 0.2 & 0.3 & 0.2 & 0.2 & 4 & 5 \\
E42M37 & 0.5 & 0.2 & .3 & 0.2 & 0.3 & 0.3 & 5 & 2 \\
E42M36 & 0.6 & 0.1 & 0.3 & 0.2 & 0.3 & 0.2 & 2 & 5 \\
E35M38 & 0.5 & 0.1 & 0.2 & 0.3 & 0.2 & 0.3 & 6 & 7 \\
Mean & 0.5 & 0.2 & 0.1 & 0.1 & 0.1 & 0.3 & 7 & 7 \\
\hline
\end{tabular}

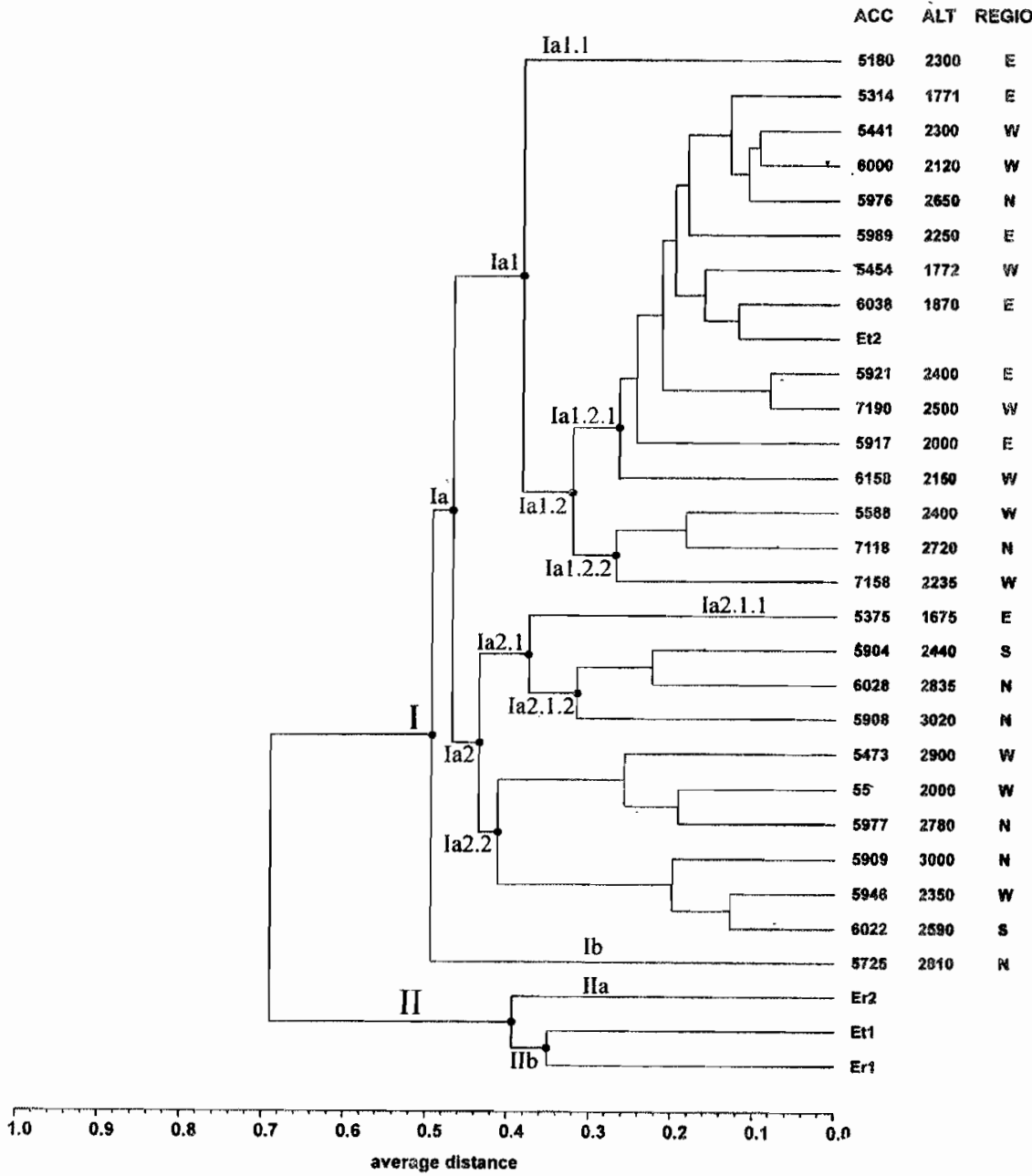

Fig. 4. UPGMA dendrogram constructed using 26 accessions and four cultivars of AFLP data. Dendrogram is labreled by altitude and sub-region classes. $\mathrm{Et}_{1} \& \mathrm{Et}_{2}$, and $\mathrm{Er} \& \mathrm{E} \mathrm{r}_{2}$ are cultivars used in this study. 
Regarding C-banding only 12 cases of pattern variation were detected between the accessions. Most striking was (sub-) distal C-band in chromosome arm 2AS, which was found only in the accessions 5909, 6028 and 5946: The two faint interstitial bands on chromosome 6A were never observed together in the Ethiopian accessions, in contrast to Capati, which shows both bands faintly. The sub telomeric band on chromosome $\mathrm{A} 7$ was distinct and observed only in accession 5921. The B-genome chromosomes showed more cases of polymorphisms. Variation in C-band size and NOR size on chromosomes $1 \mathrm{~B}, 2 \mathrm{~B}, 3 \mathrm{~B}, 5 \mathrm{~B}$ and $6 \mathrm{~B}$ are most abundant.

The profile of C-band, A- and B chromosomes, length and arm ration reveal variation between IBC accessions (Table 8). Percentage variance calculated for relative chromosomes length and arm ratio is 63.73. C-banded Shannon diversity index for accessions ranged from 0.08 to 0.96 (Table 8).

Diversity for durum and turgidum cultivars group is not informative, and that is why it is not included in this paper.

A dendrogram based on C-banding data set identified three nodes and one large group that is sub divided into three groups. Accessions 6022 and 5588 showed similarity (Fig. 5 ).

Table 8. Mean chromosome relative length, arm ratio and variation index.

\begin{tabular}{|c|c|c|c|c|c|}
\hline \multirow[t]{2}{*}{ Accession number } & \multicolumn{2}{|c|}{ Relative length } & \multicolumn{2}{|c|}{ Arm ratio } & \multirow{2}{*}{$\begin{array}{c}\text { Shannon } \\
\text { diversity } \\
\text { Index }\end{array}$} \\
\hline & $\bar{A}$ & $\bar{B}$ & $\mathrm{~A}$ & B & \\
\hline 5909 & 1.08 & 0.89 & 0.71 & 0.61 & 0.83 \\
\hline 6028 & 1.17 & 1.43 & 0.77 & 0.69 & 0.96 \\
\hline 5946 & 1.41 & 1.30 & 0.75 & 0.65 & 0.30 \\
\hline 5921 & 1.11 & 1.41 & 0.69 & 0.72 & 0.08 \\
\hline 5314 & 1.40 & 1.36 & 0.67 & 0.68 & 0.49 \\
\hline 5375 & 1.20 & 1.21 & 0.72 & 0.62 & 0.40 \\
\hline 6158 & 1.23 & 1.22 & 0.74 & 0.64 & 0.49 \\
\hline Capeti & 1.21 & 1.27 & 0.77 & 0.63 & 0.77 \\
\hline 6000 & 1.11 & 1.30 & 0.72 & 0.61 & 0.49 \\
\hline 5441 & 1.12 & 1.25 & 0.68 & 0.64 & 0.71 \\
\hline 6038 & 1.24 & 1.28 & 0.76 & 0.65 & 0.57 \\
\hline 7190 & 1.32 & 1.33 & 0.72 & 0.62 & 0.49 \\
\hline 6022 & 1.28 & 1.29 & 0.70 & 0.71 & 0.57 \\
\hline 5904 & 1.33 & 1.34 & 0.68 & 0.67 & 0.77 \\
\hline 5588 & 1.15 & 1.34 & 0.67 & 0.64 & 0.49 \\
\hline Pop.var $=0.09$ & & & & & \\
\hline S. var $=0.08$ & & & & & \\
\hline Pop.st dev $=0.29$ & & & & & \\
\hline S. st dev $=0.30$ & & & & & \\
\hline$\%$ Variance $=63.73$ & & & & & \\
\hline
\end{tabular}

\section{Capati \\ $5314 \quad 6038544159046028602255887190600059095946537561585921$}

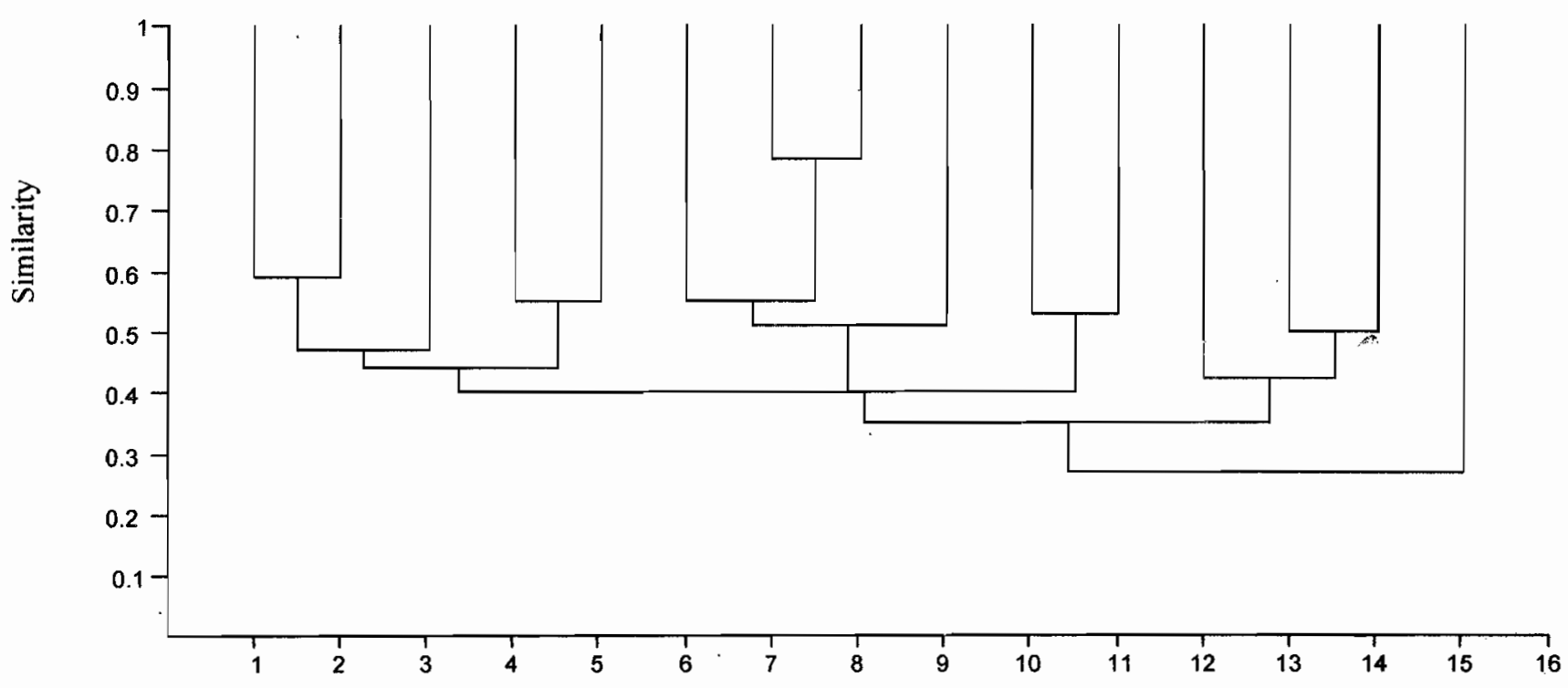

Fig. 5. UPGMA dendrogram of C-band chromosomes for $\mathrm{T} 4$ accessions and one cultivar 


\section{DISCUSSION}

This study showed that AFLP markers is useful tool for tetraploid wheat genotype identification and in detecting genetic variation. Simplicity, rapidity, and experimental reproducibility, effectiveness coupled with diagnostic ability make AFLP advantageous technique for characterization and genetic diversity study in genebank collection (Newbury and Ford-Lloyd, 1993). Our study also revealed that AFLP techinique is able to differentiate between landraces from different altitude classes and regions of collection. The reliability of AFLP in detecting genetic variation was reported by several authors: for instance, AFLP analysis to produce DNA profiling and plant variety registration in wheat was discussed in Zabeau and Vos (1995). The wheat diversity assessed by Barrett and Kidwell (1998) for classification in the gene bank showing the range of polymorphism to be 2 to 31 bands, high level of polymorphism detected in many of the cereals (Mignouna et al., 1996) and reliable transfer between population and even genera makes AFLP to be reliable technique for diversity assessment.

The high within-accession diversity and the presence of unique bands in the landraces might be ascribed to two major reasons: traditional crop mixed farming system in Ethiopian farmer's field (Law et al., 1998) and diverse out crossing potential of wheat may enhance formation of natural cross fertilization and occasional genetic recombination (Tesfaye Tessema, 1991; Harlan, 1971; Vavilov, 1951). This may have been favoured greatly to gene exchange and reassortment in the variation of Ethiopian $4 x$ wheat. The fact that the with-in accession variation (Gst) for the landraces is relatively lower compared to between cultivars shows that landraces are genetically closer among each other than the cultivars. Other reason could be the landraces co-adapted sharing similar environmental selection pressure and to a limited extent (ca.3\%) exchanging traits from the gene pool of the mixtures in which they were growing.

The existence of large number of common bands between durum and turgidum might be derived from common ancestor (Kawahara and Taketa, 2000) emmer wheat (T. turgidum). Other alternative reason could be that AFLP being a dominant marker, size of some of co-migrating loci in both cv. groups can only be observed at single locus level. The larger diversity in durum than turgidum may be associated to the frequent environmental fluctuation in Ethiopian plateau, exposing to frequent mutation, recombination and adaptation, or turgidum may be less optimised to the environment compared to durum. Human selection pressure may also be a factor for the difference in variation between the two $\mathrm{cv}$. groups.

The use of polymorphisms at the chromosomal level for biodiversity studies is still limited compared to the large variation obtained with AFLP traits. In addition, $\mathrm{C}$-band experiment is relatively laborious, time consuming as molecular markers technology. Yet C-banding studies remain irreplaceable where the detection of large translocations, inversions and other chromosomal rearrangements are considered.

The existence of unique $\mathrm{C}$-band pattern in Ethiopian accession may be related to the formation of new translocation or recent mutational rearrangements in Ethiopian $4 x$ wheats. The study conducted in fifteen tetraploid Ethiopian wheat landraces showed unique translocation supporting the indications for a monophyletic origin of Ethiopian wheat (Grubben and Soetiipto, 1996). The absence of distinct clustering (Fig. 4 and Fig. 5) for the 26 and 14 accessions studied in AFLP and Cbanding may have resulted from gene flow that support the presence of close similarity amongst the tetraploid wheat genotype.

Finally it is important to conclude that the above. approach is primarily promising for its use in gene bank, having large crop diversity, towards solving practical problems of wheat genotype identification! characterization and diversity study and help as guide to further establish in-situ and ex-situ gene banks.

\section{ACKNOWLEDGEMENTS}

I would like to thank Prof. Dr.Ir. Maarten Koornnef and Dr. Hans de Jong for their valuable technical advice. I am also indebted to Janny Wennekes for her continuous technical assistance during the laboratory work.

\section{REFERENCES}

1. Barrett, B.A. and Kidwell, K.K. (1998): AFLP-based genetic diversity assessment among wheat cultivars from the pacific northwest. Crop Sci. 38:1261-1271.

2. Edwardes, A., Civitello, A., Hammond, H.A., and Caskey, C.T. (1991). DNA typing and genetic mapping with trimeric and tetrameric tandem repeats. Am. J. Hum. Genet. 49:746-756.

3. Edwards, A., Hammond, H.A., Jin, L., Caskey, C.T. and Chackraborty, R. (1992). Genetic variation 
at five trimeric and tetrameric tandem repeat Loci in four human population groups. Genomics 12:241-253.

4. Gill, B.S., Friebe, B. and Endo, T.R. (1991). Standared karyotype and nomenclture systemes for description of chromosome bands and structural abberations in wheat (Triticum aestioum). Genome 34:830-839.

5. Grubben, G.J.H. and Soetjipto, P. (1996). Cereals. In: Plant Resources of South east Asia No: 10, pp. 136-143, (Grubben, G.J.H. and Soetjipto, P.,eds). Buckhuys Publi., Leiden, The Netherlands.

6. Harlan, J.R. (1971). Agricultural origins: centers and noncentres. Science 174:468-474.

7. Karp, A., Seberg, O. and Buiatti, M. (1996). Molecular techniques in the assessment of botanical diversity. Ann. Bot.78:143-149.

8. Kawahara, T. and Taketa, S. (2000). Fixation of translocation $2 \mathrm{~A}-4 \mathrm{~B}$ infers the monophyletic origin of Ethiopian tetraploid wheat. Theor Appl Genet 101:705-710.

9. Law, J.R., Donini, P., Koebner, R.M.D., Reeves, J.C. and Cooke, R.J. (1998). DNA profiling and plant variety registration III: The statistical assessment of distinctness in wheat using amplified fragment length polymorphisms. Euphytica 102:335-342.

10. Melaku Werede (1991). Crop genetic resources conservation and utlization: an Ethiopian perspective. A sypoosium at the 1991 AAAS annual meeting. Washington DC, pp. 103-123.

11. Mignouna, H.D., Fatokun, C.A. and Thottappilly, G. (1996). Choice of marker system. In: D NA Markers Assisted Improvement of the Staple Crops of $S u \dot{b}$ Sahran Afric. Proceedings of the workshop on DNA markers at IITA, 21-22 August 1996, pp. 9-15, (Jonathan, H., C. and Abdou Tenkouano, eds). Crop Improvement Division, ITTA, Ibadan, Nigeria.

12. Money, T., Reader, S., Qu, L.J., Dunford, R.P. and Moore, M. (1996). AFLP-based mRNA fingerprinting. Nucleic Acids Research 24(13):2616-2617.

13. Newbury, H.J. and Ford-Lloyd, B.V. (1993). The use of RAPD for assessing variation in plants. Plant Growth Regulation 12:43-51.
14. Paetku, D. and Strobeck, C. (1994). Microsatellite analysis of genetic variation in black bear accessions. Mole. Ecol 35:489-495.

15. Pfluger, La, Martin, L.M, and Alvarez, JB. (2000). Variation in the HMW and LMW glutenin sub units from Spanish accessions of emmer wheat (Triticum turgidum sspidicoccum schranck). Theor Apple Genet 102:767-772.

16. Plaschke, J., Ganal, MW and Roder, MS. (1995) Detection of genetic diversity in closely related bread wheat using microsatellite markers. Theor. Apple. Genet 91:1001-1007.

17. Qi, X. and Lindhout, P. (1997). Development of AFLP markers in barely. Mol Gen 254:330-336.

18. Robert, P. Felber, J.R. and Tom, N. (1988). NTSYG-pc Exeter software for numerical taxonomy system. Version 2.1 for windows, Rera Trade Mark.

19. Russel, J.R., Fuller, J.D., Macaulay, M., Hats, B.G., Jahoor, A., Powell, W. and Waugh, R. (1997). Direct comparison of levels of genetic variation among barely accessions detected by RFLPS, AFLP, SSRs and Rapids. Theor. Apple. Genet. 95:714-722.

20. Tesfaye Tessema (1991). Approaches towards selection of elite materials from Ethiopian durum wheat landraces: A self-pollinated crop. A paper presented at the PGRC/E-VSc Canada training workshop held in Addis Abeba, Ethiopia.

21. Tsegaye Seifu, Tesfaye Tessema and Belay Getachew (1996). Relationships among tetraploid wheat landrace accessions revealed by Isozyme markers and agronomic traits. Theor. Appl. Genet. 93:600-605.

22. Vavilov, N.I. '(1951). The origin, variation, immunity and breeding of cultivated plants. Chronica botanica 13:1-366.

23. Vos, P., Hogers, R., Bleeker, B., Reijans, M., Van de Lee, T., Hornes, M., Frijters, A., Pot, P., Peleman J., Kuiper, M. and Zabeau, M. (1995). AFLP: a new technique for DNA fingerprinting. Nuclic. Acids Res. 23:4407-4414.

24. Zabeau, M. and Vos, P. (1995). Selective restriction fragment amplification: a general method for DNA fingerprinting. European patent Application number: 92402629.7, Publication number $0534858 \mathrm{~A} 1$. 